\title{
TIME-DEPENDENT CRACK GROWTH BEHAVIORS OF FIVE SUPERALLOYS
}

\author{
Xingbo Liu, Longzhou Ma, Keh-Minn Chang \\ Department of Mechanical and Aerospace Engineering, West Virginia University \\ Morgantown, WV 26506-6106, USA
}

\begin{abstract}
Time-dependent crack growth behaviors of five superalloys, including alloys 718, 706, 783, U720 and Waspaloy, have been investigated at $650^{\circ} \mathrm{C}$ under fatigue with various holding times and sustained loading conditions. The concept of damage zone is defined as the damaged area in front of the crack tip, caused by the oxygen diffusion. A special testing procedure is designed to get the maximum damage zone of the alloy at $650^{\circ} \mathrm{C}$. U720 and Waspaloy show shorter damage zones than alloys 706 and 718 . The max damage zone size can be employed to evaluate the resistance of materials on the time-dependant FCG. The fractographical analyses show that the fracture surfaces of the specimens under hold-time fatigue conditions are mixtures with intergranular and transgranular modes. As the extension of holding time per cycle, the portion of intergranular fracture increases. The effects of loading stress intensity, temperature, holding time and alloy chemistry on damage zone and the crack growth behaviors are discussed.
\end{abstract}




\section{Introduction}

Fatigue crack growth (FCG) behavior of high temperature materials has been receiving a great deal of attention in the past decades ${ }^{1}$. It has been confirmed that there are a lot of parameters are responsible for the crack growth ${ }^{2}$. The parameters can be divided into three categories: mechanical parameters which include loading stress, frequency, loading waveform etc.; (2) material factors, which are alloy chemistry, heat treatment, microstructure etc.; and (3) environmental factors, which are test temperature and gas environments. It should be noted that the influence of the above-mentioned parameters on the deformation mechanisms and failure processes in high temperature materials depend on their interaction (parameters) in a complex manner.

In recent years, many models for FCG have been proposed based on the fracture mechanics ${ }^{3}$. It has been established that FCG rates $(d a d N)$ in metals, generally vary with the alternating stress intensity factor $\Delta K=\left(K_{\max } \quad K_{\min }\right)$. Most of the models have power law relationship (Eq. 1$)$ between $d a d N$ and $\Delta K^{3-8}$. Different exponents, $n$, have been obtained in various models.

$$
\frac{d a}{d N}=A \times(\Delta K)^{n}
$$

The role of environment in the fatigue behavior of nickel-base superalloys has to be taken into account when the life is predicted for a component in gas turbines. A number of studies have shown that the environment can play a significant role in the fracture behavior of these alloys ${ }^{9-14}$. The FCG rates of these alloys have been found to be affected by environment and are significantly increased in air as compared to that in inert gas or vacuum. The general agreement for the environmental effect has been established that, stress assisted grain boundary oxidation (SAGBO) plays the principal role in the environmental effect. Oxygen present in the air leads to the weakening of grain boundaries resulting in higher growth rates.

Although the effect of the environment has been pointed out to be responsible for the timedependent FCG behavior long ago, there is still not a correlation between the oxidation effect and the mechanics models. Also there is no particular parameter, as of now to evaluate the alloys' resistance to this kind of time-dependent behavior In this paper, the time-dependent FCG behaviors of five superalloys were investigated A new concept. damage zone, was pointed out to evaluate the materials' resistance to the environmental effect

During the cycle dependent fatigue, the material in front of the crack tip is damaged only by cyclic loading. However, if the test is conducted in air at high temperature and there is hold-time at max load in fatigue cycle, the time-dependent behaviors must be taken into consideration. Damage by cyclic loading accounts for a very less amount of the total damage of materials. During the hold-time at maximum loading, the material in front of the crack tip is damaged by the diffusion of oxygen, and the resistance against cracking is significantly lowered. During the next unloading and loading, the crack will pass through the damage zone and result in fast crack growth. This kind of crack growth is obviously time-dependent. The size of damage zone represents the resistance of materials against the crack growth. Therefore, a new concept, damage zone is defined as: the area in front of the crack tip, where the material is damaged by the oxygen diffusion and the resistance of material to crack growth is lower than a criterion which can prevent the crack growth during the fatigue cycle.

General speaking, in the hold-time fatigue tests, the damage zone is very small and it cannot be measured for each cycle. In this paper, a special test sequence is provided to confirm the 
existence of damage zone and measure the maximum damage zone size of the material under certain temperature and load condition. The effect of temperature on the damage zone size of materials was investigated. A detailed discussion on the crack growth behavior was provided.

\section{Experiments}

\section{Materials and Specimens}

Five superalloys, alloys 706, 718, Udimet 720, Waspaloy and Inconel 783, were chosen for testing. Alloys 706, 718, U720 and Waspaloy are superalloys available for a long time. Inconel 783 is a recently developed oxidation-resistant, low coefficient of thermal expansion superalloy $^{15}$. To research the $\beta$ (NiAl) phase effect on the hold-time FCG behavior of Inconel 783, two heat treatment plans of the alloy were employed in this investigation. The chemical compositions of the materials are listed in Table I. All the specimens were cut from a commercial premium grade forging bar. The commercial standard heat treatments were applied to the sample blanks as shown in Table II.

Table I: Chemical Compositions of Tested Materials (wt \%)

\begin{tabular}{|c|c|c|c|c|c|c|c|c|c|c|}
\hline Alloy & C & $\mathrm{Fe}$ & $\mathrm{Ni}$ & $\mathrm{Cr}$ & $\mathrm{Al}$ & Tí & Co & Mo & $\mathrm{Nb}$ & $W$ \\
\hline $\ln 718$ & 0.033 & 17.94 & Bal. & 18.41 & 0.56 & 0.91 & -- & 3.03 & 4.98 & -- \\
\hline $\ln 706$ & 0.021 & 36.84 & Bal. & 16.07 & 0.23 & 1.85 & 0.028 & 0.05 & 3.05 & 0.001 \\
\hline U720 & 0.013 & 0.14 & Bal & 1614 & 2.48 & 515 & 1445 & 285 & -- & 1.18 \\
\hline Waspaloy & 0.019 & 0.38 & Bal & 19.55 & 1.37 & 2.95 & 13.51 & 4.25 & 0.01 & 0.06 \\
\hline $\ln 783$ & & 24.88 & 28.21 & 3.24 & 5.32 & 0.32 & 34.39 & -- & 311 & -- \\
\hline
\end{tabular}

Table II. Heat Treatments of the Test Materials

\begin{tabular}{ll} 
Alloy & Heat Treatment \\
\hline In718 & $980^{\circ} \mathrm{C} / 1 \mathrm{~h} / \mathrm{AC}+720^{\circ} \mathrm{C} / 8 \mathrm{~h} / \mathrm{FC} \rightarrow 620^{\circ} \mathrm{C} / 8 \mathrm{~h} / \mathrm{AC}$ \\
In706 & $980^{\circ} \mathrm{C} / 1 \mathrm{~h} / \mathrm{AC}+843^{\circ} \mathrm{C} / 3 \mathrm{~h} / \mathrm{AC}+720^{\circ} \mathrm{C} / 8 \mathrm{~h} / \mathrm{FC}\left(55^{\circ} \mathrm{C} / \mathrm{h}\right) \rightarrow 620^{\circ} \mathrm{C} / 8 \mathrm{~h} / \mathrm{AC}$ \\
U720 & $1105^{\circ} \mathrm{C} / 2 \mathrm{~h} / \mathrm{OQ}+760^{\circ} \mathrm{C} / 8 \mathrm{~h} / \mathrm{AC}+650^{\circ} \mathrm{C} / 24 \mathrm{~h} / \mathrm{AC}$ \\
Waspaloy & $1020^{\circ} \mathrm{C} / 4 \mathrm{~h} / \mathrm{OQ}+850^{\circ} \mathrm{C} / 4 \mathrm{~h} / \mathrm{AC}+760^{\circ} \mathrm{C} / 16 \mathrm{~h} / \mathrm{AC}$ \\
In783(no $\beta)$ & $1120^{\circ} \mathrm{C} / 1 \mathrm{~h} / \mathrm{WQ}+720^{\circ} \mathrm{C} / 8 \mathrm{~h} / \mathrm{FC} \rightarrow 620^{\circ} \mathrm{C} / 8 \mathrm{~h} / \mathrm{AC}$ \\
In783 (B) & $1120^{\circ} \mathrm{C} / 1 \mathrm{~h} / \mathrm{AC}+845^{\circ} \mathrm{C} / 4 \mathrm{~h} / \mathrm{AC}+720^{\circ} \mathrm{C} / 8 \mathrm{hC} \rightarrow 620^{\circ} \mathrm{C} / 8 \mathrm{~h} / \mathrm{AC}$ \\
\hline
\end{tabular}

Note: AC - Air Cooling; FC - Furnace Cooling; OQ - Oil Quench; WQ - Water Quench

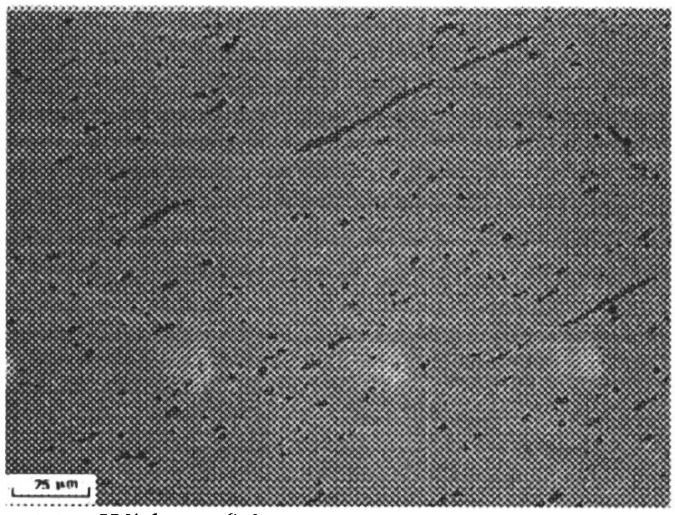

(a) - Without $\beta$ heat treatment

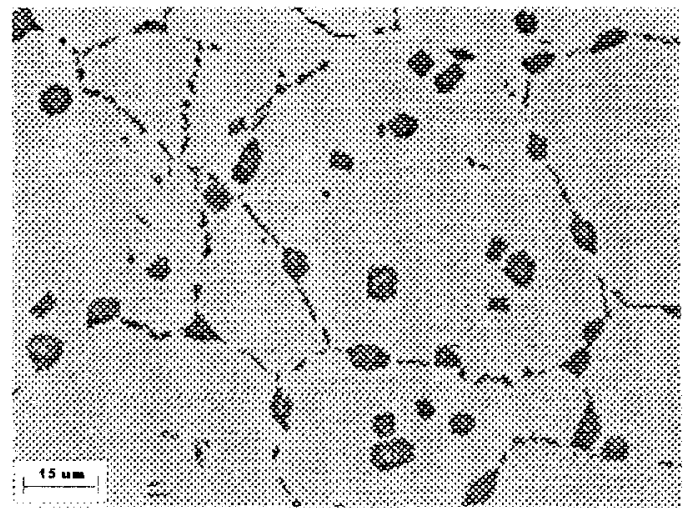

(b) - With $\beta$ heat treatment

Figure 1: SEM Metallurgraphs of $\ln 783$ under various heat treatments 
The SEM metallographs of $\operatorname{In} 783$ experienced with $\beta$ and without $\beta$ heat treatments are shown as Fig. 1. There are continuous $\beta$ precipitates along grain boundaries of the specimen under $\beta$ treatments. On the contrary, for the one under no $\beta$ treatments, only a few $\beta$ particles, which are believed to be the leftover during the solution stage, are found at grain boundaries

Single-edge-notched (SEN) plate type of specimens with a gauge section of $3.2 \mathrm{~mm}$ thickness and $19 \mathrm{~mm}$ width were employed in the crack growth tests. The dc potential drop technique was utilized to monitor crack length during tests. A 3.81 -mm-deep notch was introduced at the center of the opposite edge of current outlets by a wire electro-discharge-machine (EDM). Each specimen was pre-cracked at a low $\Delta \mathrm{K}$ level for $1.25 \mathrm{~mm}$ crack growth away from the EDM notch. This procedure ensured that the crack growth reached a steady state and was no longer affected by the starter notch geometry

\section{Fatigue Crack Growth Tests}

The SEN specimens were tested in a closed-loop MTS 8100 servo-hydraulic system. The testing procedure was controlled and recorded by the computer software, which was developed by West Virginia University. The specimen was pre-cracked up to $2.54 \mathrm{~mm}$ with low stress intensity triangle cycles at room temperature. Then the specimen was heated to a higher temperature and FCG tests were carried out at $538^{\circ} \mathrm{C}$ and $650^{\circ} \mathrm{C}$. The loading cycles included 3 seconds triangle waveform and trapezoid waveform with 3 seconds ramp and different hold-time at max load. Finally the specimen was broken to calibrate the crack size

\section{Characterization of maximum Damage Zone}

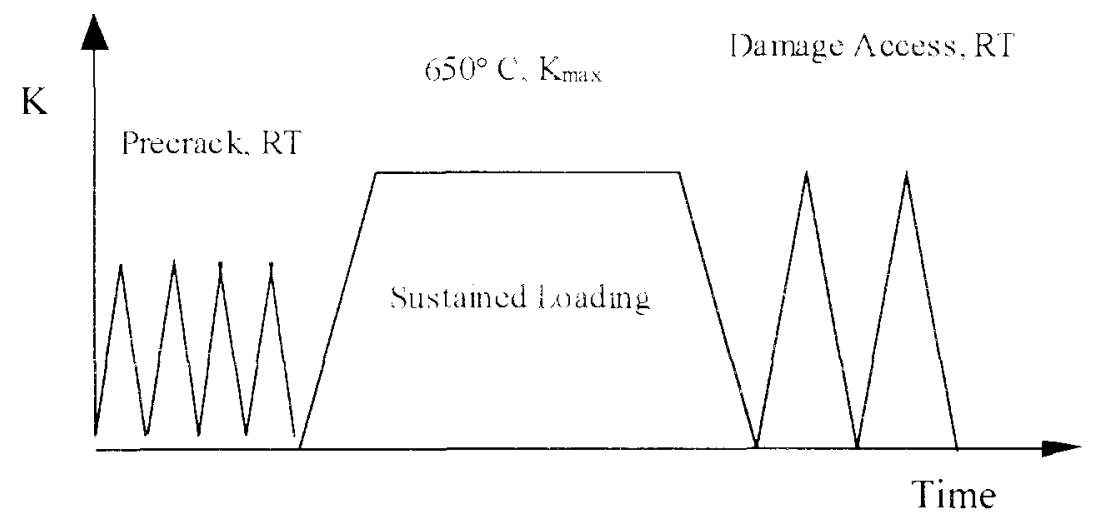

Figure 2: A sketch of the testing procedure to measure the damage zone

As illustrated in the introduction, the maximum damage zone sizes of the materials were measured in this study. As shown in Fig. 2, the specimen was pre-cracked with a low stress intensity triangle cycles up to at least 1.25 or $2.5 \mathrm{~mm}$. Then the specimen was heated to a higher temperature and was subjected to constant stress intensity sustained loading. After a period of sustained loading, it was cooled to the room temperature and the fatigue tests were conducted with the frequency of $1 / 6 \mathrm{~Hz}$. The max $K$ employed in this case was same as that of sustained loading. The max damage zone sizes of the materials were obtained from this test sequence. Also, the effect of temperature and the stress intensity on the Damage Zone size of material was investigated in this study. 


\section{Experimental Results and Discussions}

\section{Hold-Time Fatigue Crack Growth}

Fig. 3 shows the FCG rates of Waspaloy, U720, 706 and 718 as a function of holding time at the maximum stress intensity at $650^{\circ} \mathrm{C}$. It is indicated that all of the four alloys have similar growth rates under $3 \mathrm{~S}$ loading. The crack growth rates of $3+10 \mathrm{~S}$ and $3+30 \mathrm{~S}$ show obvious timedependence for U720, In706 \& In718. With the increase in holding time, the growth rates increase linearly for these three alloys. The beneficial effect of $\beta$ phase on hold-time FCG of alloy 783 is shown as Fig. 4. The hold-time FCG rate of the alloy with $\beta$ phase is much lower than that without $\beta$ phase. Table III shows the time-dependency of the FCG of the alloys. $\Delta(\mathrm{da} / \mathrm{dN}) / \Delta\left(\mathrm{t}_{\text {hold }}\right)$ are the slopes of the trend-lines in Fig.s $3 \& 4$. The larger of $\Delta(\mathrm{da} / \mathrm{dN}) / \Delta\left(\mathrm{t}_{\mathrm{hold}}\right)$, the stronger of the FCG of the alloy. It is clear that Inconel 783 with $\beta$ has the best resistance to the hold-time FCG and alloy 718 shows the strongest time-dependency of FCG. Waspaloy and U720 show better resistance against the hold-time crack growth than alloys 706 and 718 . The crack growth rates of Waspaloy and alloy 783 with $\beta$ phase are cycle dependent with less than 30 seconds holding under $650^{\circ} \mathrm{C}$.

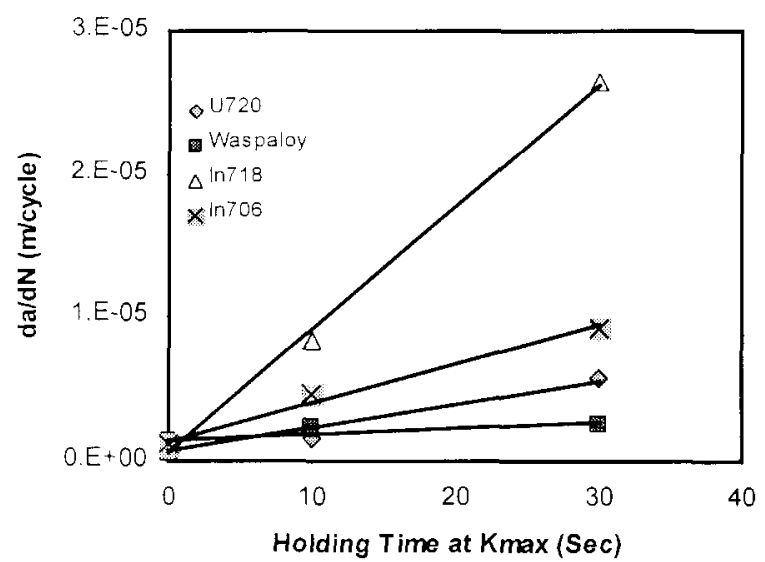

Figure 3: FCG rates of the superalloys as a function of holding time at maximum load.

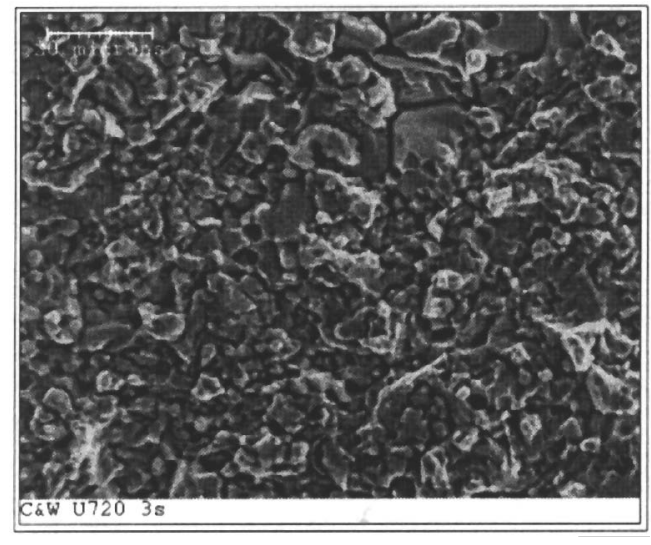

(a) - Fatigue, 3S, U720

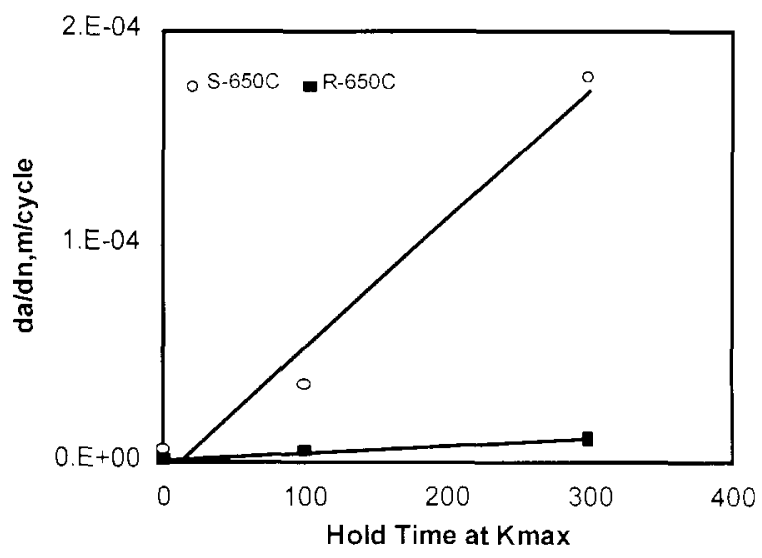

Figure 4: FCG rates of $\operatorname{In} 783$ under various heat treatment as a function of hold-time.

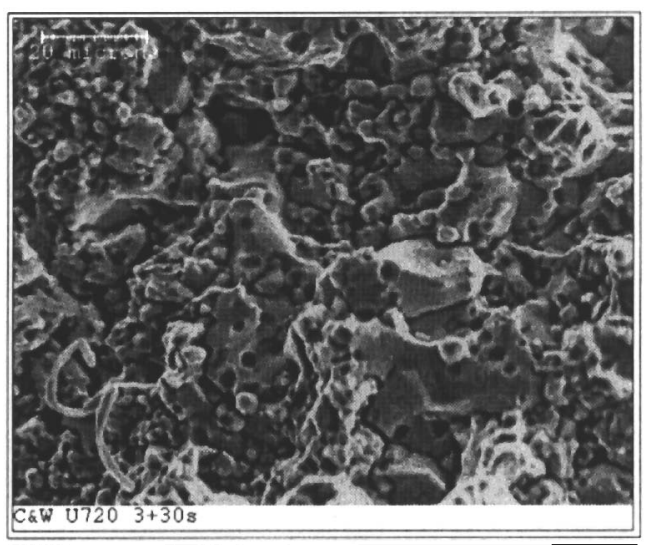

(b) - Fatigue, $3+30$ S, U720

Figure 5: SEM Fractography of U720 Fatigue Failed Surfaces. 
Table III: Time-dependency of the FCG of the alloys

\begin{tabular}{ccccccc}
\hline Alloy & Waspaloy & U720 & 706 & 718 & $783($ no $\beta)$ & $783(\beta)$ \\
\hline $\begin{array}{c}\Delta(\mathrm{da} / \mathrm{dN}) / \Delta\left(\mathrm{t}_{\text {hold }}\right) \\
\left(\mathrm{m} / \mathrm{s}^{2}\right)\end{array}$ & $4.22 \times 10^{-8}$ & $1.16 \times 10^{-7}$ & $2.67 \times 10^{-7}$ & $8.52 \times 10^{-7}$ & $5.97 \times 10^{-7}$ & $3.38 \times 10^{-8}$ \\
\hline
\end{tabular}

Fractography analyses of the fractured surfaces of the specimens was conducted by means of SEM. Typical graphs of U720 are shown in Fig.5. It is clear that the fracture mode of fatigue at $650^{\circ} \mathrm{C}$ is mixture of both intergranular and transgranular with secondary crack, regardless of the difference in holding time. The proportion of intergranular crack increases with the increase of hold time. The large number of small particles are believed to be primary $\gamma^{\prime}$.

\section{Damage Zone Characterization of the Alloys}

Fig.s 6 and 7 show the typical crack growth behaviors of U720 during damage zone characterization. The existence of a damage zone in front of the crack tip was confirmed by the curves. The crack growth rate, which is the first derivative of the curve, was remarkably different for each point of the curve. Comparing with the final crack growth rate (Fig.7), the crack grew much faster in the material closer to the crack tip after sustained loading. The $d a / d N$ within damage zone decreases monotonically with the crack length. It is clear that the damage is localized and the material outside the damage zone is not damaged. The size of damage zone formed during sustained loading can be easily measured in Fig.7.

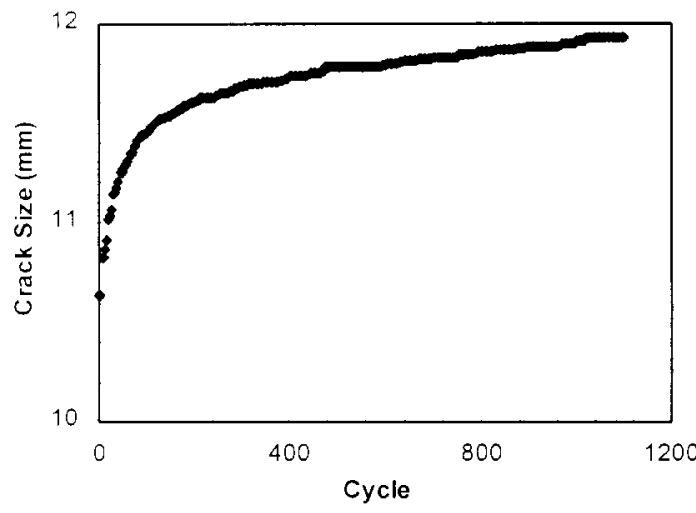

Figure 6: Typical Crack Growth Curves during the Damage Zone Characterization of U720 at room temperature.

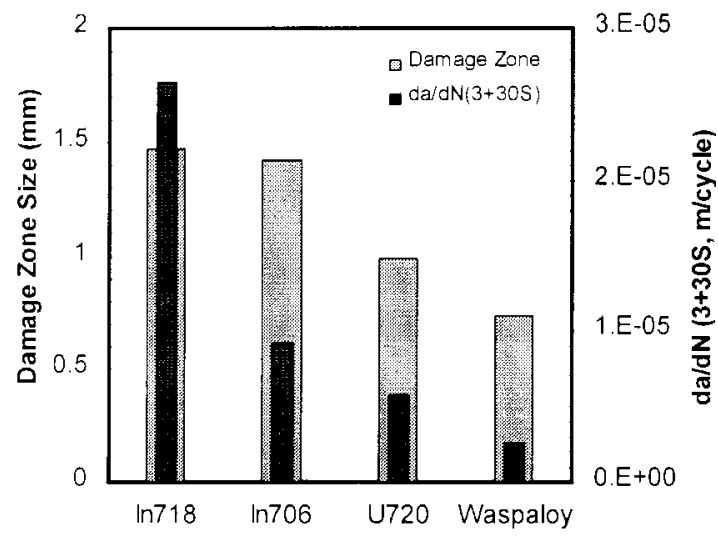

Figure 8: Comparison on the damage zone sizes and hold-time FCG $(3+30 \mathrm{~S})$ rates of the alloys.

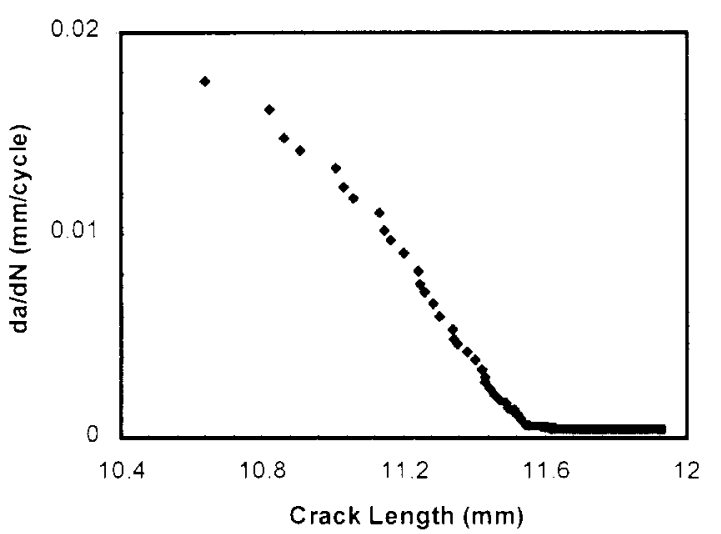

Figure 7: Relationship between da/dN and crack length during Damage Zone Characterization of U720.

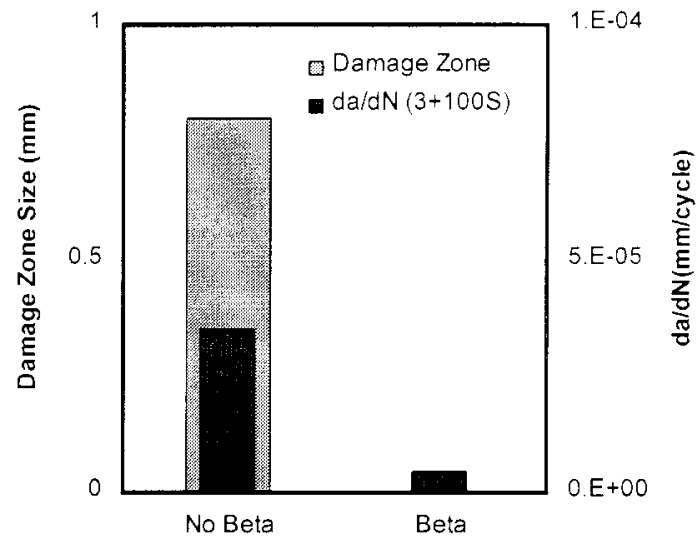

Figure 9: Comparison on the damage zone sizes and hold-time $\mathrm{FCG}(3+100 \mathrm{~S})$ rates of In783 under various heat treatments. 
Fig. 8 shows the comparison on the damage zone sizes and the hold-time FCG rates of 718, 706, U720 and Waspaloy. The damage zone sizes of 718 and 706 are higher than that of U720 and Waspaloy. Comparing the damage zone sizes with FCG rates, it can be inferred that the holdtime FCG increases as of the damage zone size. Therefore, the damage zone size of the materials can be employed to evaluate the its' resistance to time-dependent FCG. The alloy with smaller damage zone size has better resistance to time-dependent crack growth. The beneficial effect of $\beta$ phase on the hold-time FCG behavior of In783 are shown as Fig.9. It was found that $\beta$ phase prevent the formation of damage zone at $650^{\circ} \mathrm{C}$. The crack of the specimen with $\beta$ phase did not growth after 60 hours holding. There is no damage zone show up during the following damage access stage. The hold-time FCG rate of the one with $\beta$ phase is much lower than the one without $\beta$, although the cycle-dependent FCG rates of the alloy under various heat treatments are similar. $\beta$ phase improves the resistance of the alloy to SAGBO.

\section{Temperature Effect on Damage Zone Size}

As shown in Fig. 10, the damage zone sizes of the alloys increase with the testing temperature. The damage zone size under a certain temperature is different for different alloys. In spite of loading for more than 60 hours at $538^{\circ} \mathrm{C}$ and at a $\mathrm{K}$ of $38.4 \mathrm{MPa}^{*} \mathrm{~m}^{1 / 2}$, there was still no crack growth and damage zone formation for U720 and Waspaloy, while a damage zone size of $0.635 \mathrm{~mm}$ was found for 706 at $538^{\circ} \mathrm{C}$. Fig. 10 was re-plotted as Fig. 11 with Log (Damage Zone Size) vs. 1/Temperature. It was found that the lines obtained were parallel each other and the slope for the three alloys were almost the same. This implies that the formation of a damage zone is a thermal-activated process and the activation energies for the alloys are almost the same.

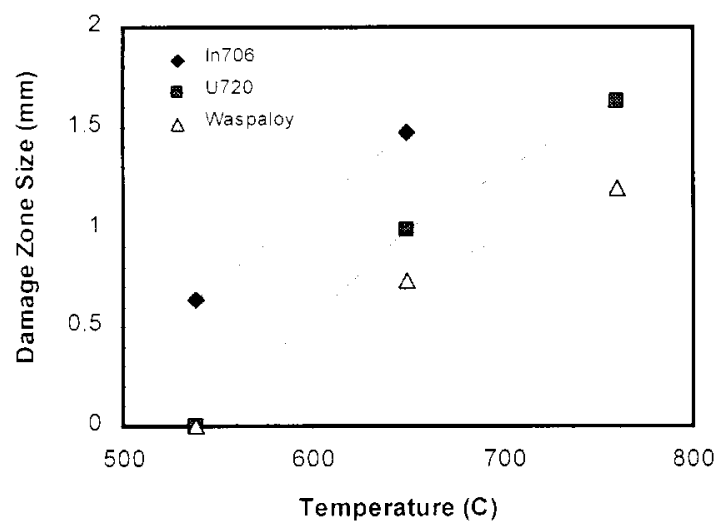

Figure 10: Temperature Effect on the Damage Zone Sizes of the Alloys.

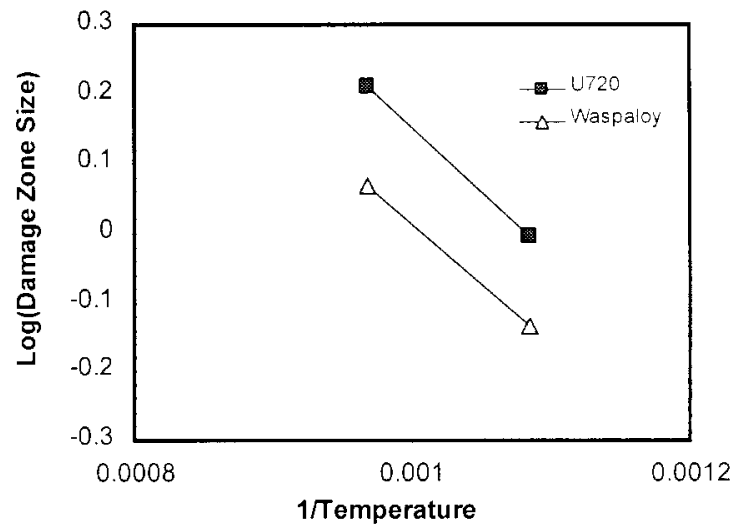

Figure 11: Re-plot Fig. 10 as Log(Damage Zone Size) vs. 1/Temperature.

\section{Discussions}

\section{Damage zone size and crack growth rate of the alloys}

The existence of damage zone in front of the crack tip has been confirmed by the special designated test sequence. The FCG rate within damage zone is faster than normal one. The material within the area was damaged during the high temperature sustained loading. This kind of damage is the result of environmental effect. The appearance of oxygen has been well accepted as the primary reason of the environmental degradation. Oxygen diffuses into the material in front of the crack tip and decreases the resistance of the material to crack growth. The 
diffusion is thermal-activated time-dependent behavior, and the grain boundary is a fast channel for the diffusion. The damaged grain boundary has lower resistance to crack growth. Therefore,

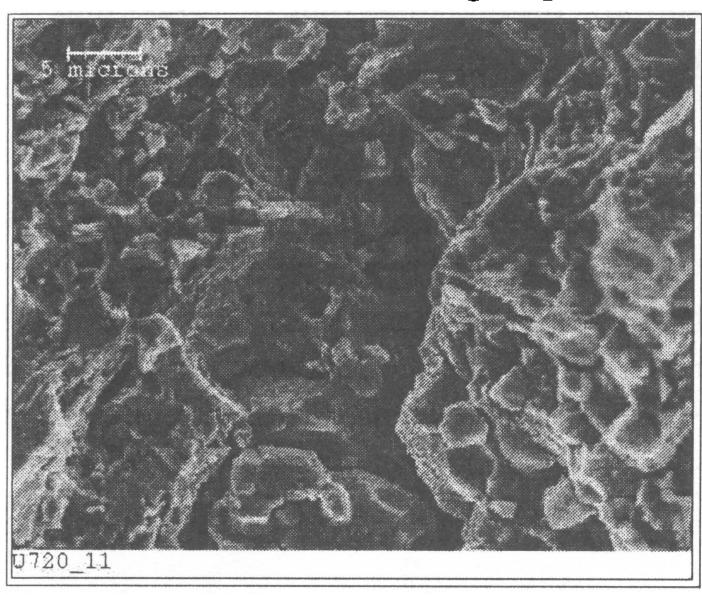

Figure 12: SEM fractography of damage zone of U720 after fatigue test at room temperature. unlike the transgranular fracture during cycledependent fatigue, the fracture surface of the specimen during time-dependent fatigue becomes intergranular. As shown in Fig. 12, the fracture surface shows the intergranular failure mode in damage zone, even the fatigue test was carried out at room temperature. The level of damage at grain boundary is supposed to be related to the contents of oxygen there. Therefore, the size of damage zone depends on the profile of oxygen contents in front of the crack tip.

As proposed by Spediel ${ }^{16}$, any difference in $d a / d N$ observed for materials operated under cycle dependent conditions (e.g. room temperature or in a vacuum environment), can be mainly explained by

the difference in elastic modulus. Testing parameters, such as cycle period and waveform, play a negligible role in determining the growth rate for a fixed $\Delta K$. Actually, stage II FCGR has been considered to be insensitive to the variations in microstructure and alloy chemistry. The testing results in this investigation confirm the viewpoint of Spediel. It is revealed in Fig.s 3 and 4 that the FCG rates of all the alloys, under 3 seconds triangle waveform loading, are almost the same. However, the FCG rates with various hold times are different because of the difference of the alloys' resistance to SAGBO. Fig. 8 and 9 shows the relationship between damage zone size and hold-time FCG rates of the alloys. It is revealed that the alloys has better resistance of SAGBO (smaller damage zone size) also has a lower hold-time FCG rate.

\section{Temperature and Load effect on damage zone size}

In general, the crack growth rates under both of the cycle-dependent and time-dependent conditions will increase as of the stress intensity factor and temperature. Under time-dependent condition, the increasing of the applied load and temperature promotes the oxygen diffusion.

$$
D=D_{0} \times \exp \left(\frac{-Q}{k T}\right)=D_{0} \times\left(\frac{-Q_{0}+f(\sigma)}{k T}\right)
$$

Eq. (2) is the basic equation to calculate the diffusion coefficient, where $D$ is the diffusion coefficient, $D_{0}$ is an constant, $k$ is the Boltzmann constant, $T$ is the absolute temperature, $Q$ is the activation energy for diffusion, $Q_{0}$ is the activation energy without load, $f(\sigma)$ is an function of applied load. As the increasing of applied load, the activation energy $Q$ was lowered and the diffusion of oxygen was accelerated. It is expected that $f(\sigma)$ increases with the applied load.

It can be obtained from Eq. (2) that both applied load and temperature accelerate the oxygen diffusion in front of the crack tip, $D$ increases as of both applied load and temperature. Therefore, it is safely concluded that both applied load and temperature will increase the holdtime FCG rates of the alloys, based on the damage zone idea.

\section{Effect of Alloy Chemistry}


It is shown in Fig. 3 that the FCG rates of all alloys at $3 \mathrm{~S}$ loading are almost the same in spite of the difference of the alloy chemistry and heat treatment. However, as the holding time increasing, Some alloys, such as U720 and Waspaloy, show better resistance to the hold-time fatigue crack propagation.

Since the dominant fracture mode of the alloys under hold-time fatigue condition is intergranular, the chemical compositions and properties of the grain boundaries play the most important roles on hold-time FCG behaviors of the alloys. Superalloy is a complicated alloy system and there is a significant difference of the chemical compositions between one alloy and the others. Furthermore, the segregation behaviors of some alloy elements toward the grain boundaries lead to the big difference of the compositions between grain boundaries and grain inside. Then the chemical compositions and the mechanical properties of the alloys' grain boundary are not quantitative predictable.

According to the damage zone idea, during the hold-time FCG, the interaction between oxygen and the alloy elements at the alloy's grain boundaries and its effect on the diffusion behavior of oxygen must be taken into consideration. The difference of the chemical compositions of the alloys' grain boundary causes the various diffusion behavior of oxygen in front of the crack tip. The FCG results show that the grain boundary of Waspaloy has the best resistance to the oxygen diffusion and the resistance of alloy 718 is the worst. In general, the complicated interaction between the alloys' grain boundary and oxygen and its effect on hold-time FCG behavior need to be further investigated in the future.

\section{Summary and Conclusions}

A new parameter, damage zone, to investigate the crack growth behavior during hold-time fatigue was pointed out in this paper. Damage zone is defined as: the area in front of the crack tip, where the material is damaged by the oxygen diffusion and the resistance of material to crack growth is lower than a criterion which can prevent the crack growth during the fatigue cycle. It is clear that during the hold-time fatigue, damage zone formed within one cycle equals to the crack growth rate $d a / d N$, which is the function of stress intensity factor, temperature and hold-time. However, since the damage zone formed within one cycle is too small to be measured accurately, a special designed test procedure was carried out to confirm the appearance of damage zone during the high temperature holding, and then the maximum damage zone size, which is the function of stress intensity factor and temperature, was obtained in the test. It was the max damage zone size under certain loading and temperature can be employed to evaluate the alloy's resistance to the hold-time fatigue crack growth. Several conclusions were made based on this investigation:

1. The FCG rates of the alloys under 3 seconds triangle waveform loading at $650^{\circ} \mathrm{C}$ are almost the same, while the difference show up under hold-time fatigue condition. Waspaloy shows the best resistance to hold-time FCG, while the resistance of U720 is better than that of alloys 706 and 718 .

2. A beneficial effect of $\beta$ phase on the hold-time FCG behavior of Inconel 783 was found in this investigation. The specimen with $\beta$ shows little time-dependence on hold-time FCG, while the specimen without $\beta$ appears strong time-dependence on hold-time FCG.

3. The max damage zone sizes of several alloys were obtained by a special designed test sequence. Alloy 718 has the largest damage zone size and Waspaloy has the smallest one. The max damage zone size of alloy 706 is larger than U720. For Inconel 783, the appearance of $\beta$ phase prevent the formation of damage zone at $650^{\circ} \mathrm{C}$, It is indicated that the maximum 
damage zone size can be employed to evaluate the resistance of the alloy on the hold-time FCG.

4. The effects of temperature and applied load on damage zone size and hold-time FCG were discussed. Both temperature and applied load can accelerate the oxygen diffusion in front of the crack tip and then reduce the alloys' resistance to FCG. The analysis shows that the formation of damage zone is a thermal activation process and the activation energy for the alloys is same.

\section{Reference:}

1. L. Garimella, P. Liaw and D. Klarstrom, JOM, 49 (1997), No.7, 67-71.

2. M. Cao, F. Gabrielli and R. Pelloux, Res Mechanica, 17 (1986), 163-177.

3. T. Sudershan and M. Louthan, Jr, Int. Mat. Rev., 32 (1987), 121-151.

4. D. Davidson and J. Lankford, Int. Mat. Rev., 37 (1992), 45-75.

5. P. Paris and F. Erdogan, J. Basic Eng. (Trans. ASME), 85 (1963), 528-534.

6. J. Lanteigne and J-P. Bailon, Met. Trans. A. 12A (1981), 459-466

7. B. Tomkins, Philos. Mag. 18 (1968), 1041-1066.

8. S.D. Antolovich, A. Saxenta and G.R. Chanati: Eng. Frac. Mech.. 17 (1975), 649-52.

9. M. Stroosnijder, V, Guttmann and J.H.W. de Wit: Met. \& Mat. Trans. A. 26A (1995), 21032110.

10. A. McEvily and J.L. Velazquez, Met. Trans. A. 23A (1992), 2211-2221.

11. H. Smith and D. Michel, Met. Trans. A, 17A (1986), 370-374.

12. I. Vasatis and R. Pelloux, Met. Trans. A, vol.16A (1985), 1515-1520.

13. L. Korusiewicz, J. Dong and M. Kumosa: Scripta Met. et Mat., 29 (1993), 573-578.

14. E. Fleury and L. Remy: Mat. Sci. \& Eng. A, A167 (1993), 23-30.

15. K.A. Heck, J.S. Smith and R. Smith, Int. Gas Turbine and Aeroengine Congress \& Exhibition, 1996, -8.

16. M. Speidel, High Temperature Materials in Gas Turbines.(Elsevier, 1974), 207.

17. M. Gao, et al., Elevated Temperature Effects on Fatigue and Fracture, ASTM STP 1297, (West Conshohocken, PA: ASTM, 1997), 74-84. 